\title{
CERTIFICAÇÃO PARA FINS DE EXPORTAÇÃO: UM CASO DE PEQUENA MANUFATURA DO RAMO MÉDICO HOSPITALAR- ODONTOLÓGICO
}

\section{EXPORT CERTIFICATION: A CASE OF SMALL A MANUFACTURING COMPANY OF DENTAL, MEDICAL AND HEALTH SECTOR}

\author{
Luciana Oranges Cezarino ${ }^{1}$; Helds Massashi Ishi ${ }^{2}$; Hamilton Luiz Correa ${ }^{3}$ \\ ${ }^{1}$ Faculdade de Economia, Administração e Contabilidade - FEA/USP- São Paulo - Brasil \\ lucezarino@hotmail.com \\ ${ }^{2}$ Faculdade de Economia, Administração e Contabilidade - FEA/USP- São Paulo - Brasil \\ hamillco@usp.br \\ ${ }^{3}$ Universidade de Ribeirão Preto - UNAERP - Ribeirão Preto - Brasil \\ heldaoxxx@hotmail.com
}

\begin{abstract}
Resumo
$O$ artigo investiga as condições em que a certificação para fins de exportação tem ocorrido no meio industrial de pequeno porte tomando como exemplo uma manufatura do ramo médico hospitalar-odontológico de Ribeirão Preto. Exploratoriamente e por meio de estudo de um caso foram observadas que as principais causas para esse processo foram externas à organização. $O$ mercado internacional, câmbio e outros fatores favoráveis à venda deste produto induziram a certificação. Todo o processo foi conduzido por agentes externos de mudança: consultorias e foi trabalhado como diferencial para a organização atingir novos mercados. Como consideração percebeu-se que a exportação ocorreu de forma reativa e sem maiores alinhamentos à estratégia organizacional, porém responsável por mudanças relevantes nos processos internos da organização.
\end{abstract}

Palavras-chave: exportação; pequena empresa; exportação

\section{Introdução}

Segundo Robbins (2000) as fronteiras nacionais delimitavam espaço para empresas em um determinado território, porém essa delimitação descaracterizou-se dando ênfase a um processo denominado globalização, a qual desinstalou as barreiras geográficas entre territórios nacionais, gerando a expansão de produtos, serviços e informações.

Devido a esse processo, atualmente é irrelevante atrelar a empresa ao seu país de origem, porque em muitos casos as instalações físicas das fábricas estão, estrategicamente, localizadas em 
outros locais. Ao atravessar as barreiras territoriais à empresa insere-se em um mercado global onde pode prospectar novos mercados e buscar redução de custos, porém estará sujeita, também, a um número expressivamente maior de concorrência, ao passar de nacional para internacional.

A análise, segundo Dias (2004) por esta perspectiva, permite concluir que a economia mundial está deixando de ser um agregado de economias nacionais para, gradualmente, converter-se em empresas participantes de um único sistema econômico global.

Exportar, segundo Vazquez (1999) é uma forma de inserção na economia global e um método para gerar divisas econômicas e formação de reservas para novas aquisições. A grosso modo, a empresa exportadora contribui economicamente para o superávit econômico do país e pode reter capital para reinvestimentos.

Além de evitar crises devido a períodos de sazonalidade interna, ou seja, períodos em que há baixa demanda interna reduzem os riscos, pois a empresa não é mais sujeita à oscilação de um restrito mercado: a exportação pode aumentar o prestígio da marca no país de origem, pois para exportar deve-se, no mínimo, adequar-se a padrões de qualidade mais exigentes.

Essas vantagens e impactos decorrentes do processo de globalização ficam ainda mais preponderantes dentro do contexto das pequenas empresas que lidam com tecnologia. A necessidade de profissionalização requerida pelo processo de exportar é um dos desafios que essas empresas enfrentam.

Setores em que há necessidade de trabalhar com tecnologia e certificações são exemplos de como essas empresas devem se comportar nesse contexto. O ramo da indústria hospitalarodontológica é um arquétipo brasileiro de inserção no contexto internacional globalizado pela exportação de um produto considerado de média a alta intensidade tecnológica. Para tanto, esforços de profissionalização de processos e engenharia tem sido empregados, principalmente, na região da cidade de Ribeirão Preto-SP para a obtenção de certificações que legitimem sua qualidade em produtos a serem vendidos no mercado mundial.

Porém, a principal dificuldade encontrada por essas empresas se dá após a decisão de certificar-se quando os desafios e problemas de mudança organizacional são vistos e sentidos pela empresa.

Diante dessas informações, cabe a seguinte questão de pesquisa: Quais são as principais questões organizacionais para certificação internacional de micro e pequenas empresas do ramo Médico-Hospitalar-Odontológico (MHO) de Ribeirão Preto?

No decorrer deste artigo o objetivo geral e o método de pesquisa serão descritos, posteriormente explica-se sobre as referências de literatura utilizadas e por fim, os resultados são expostos e algumas considerações extraídas. Também são apontadas limitações e futuras pesquisas. 


\section{Objetivos e método}

Esse trabalho pretende avaliar as questões envolvidas no processo de certificação para a atuação de pequenas e médias empresas do ramo MHO de Ribeirão Preto em mercado internacional. Para isso será necessário entender através de aspectos teóricos a internacionalização envolvendo certificações de produtos e processos de pequenas e médias empresas do setor MHO na literatura de comércio exterior; determinar quais são as exigências de gestão que as micro e pequenas empresas têm que enfrentar neste contexto; utilizar-se de um caso de empresa MHO de Ribeirão Preto para ilustrar o fenômeno contextualizado empiricamente; e estar apto a gerar considerações sobre o assunto.

Para sua execução de natureza exploratória, vinculou-se a abordagem qualitativa a fim de que o objetivo da pesquisa seja alcançado. A pesquisa exploratória, segundo Cervo (2006) em termos gerais desenvolve a formulação de hipóteses relevantes para a fundamentação da pesquisa. Esta realiza descrições fundadas para a situação estudada e funde elementos relacionando-os entre seus componentes.

A afirmação feita por Cervo é ratificada em Gil (1991) o qual refere-se à pesquisa exploratória como estruturação dos dados com posterior fundamentação e devido conhecimento do problema abordado, a estruturação e fundamentação da pesquisa se da através da sedimentação dos dados baseando-se em suporte bibliográfico do tema referido.

Visto isso, a abordagem qualitativa, a qual não mensura quantificações numéricas em sua proposta, segundo Oliveira (1997) busca apresentar adequadamente e fazer entender a relação causa e efeito do fenômeno e conseqüentemente chegar a sua verdade e razão. Tem-se a abordagem qualitativa para o referido trabalho, pois o tema abordado possui variáveis subjetivas e correlacionáveis as quais tornam este estudo o mais adequado a situação.

Em linhas mais especificas, Goldenberg (1999) menciona que a pesquisa qualitativa proporciona dados mais sólidos sobre as variáveis humanas, organizacionais e institucionais através de contato direto com pesquisador e objeto de estudo. Esses dados, conforme Garcia (1998) são transformados em variáveis passíveis de manipulação para que os resultados possam ser alcançados. Desta forma utiliza-se de técnicas estatísticas para que as informações sejam obtidas.

O método utilizado é o estudo de caso, pois possibilita grande flexibilidade no decorrer do desenvolvimento do trabalho desprendendo-o de moldes pré-fixados, segundo Gil(1991). Dentre as técnicas de pesquisas sociais existentes a que melhor se encaixa neste objeto de estudo é o estudo de caso. Apesar de sua simplicidade, Castro (1977) pondera que é melhor fazer uso de uma técnica simples que em vez de procurar técnicas sofisticadas apenas porque estão disponíveis. Boyd e Stasch (1985) também colocam que é dada ênfase à completa descrição e ao entendimento do 
relacionamento dos fatores a cada situação, não importando os números que estão envolvidos. Para finalizar Campomar (1991) ainda ressalta que o uso intensivo em um caso permite a descoberta de relações que não seriam encontradas de outra forma sendo as análises e inferências em estudos de casos feitas por analogias de situações, respondendo principalmente às questões por quê? E como?

Os dados para fundamentação do estudo foram coletados por meio de entrevista como o diretor-presidente na empresa Dentflex Indústria e Comercio Ltda. Justifica-se a utilização da DentFlex como exemplo de um caso de certificação para exportação por se tratar de uma empresa pequena, com padrão tecnológico médio e que direciona parte de seu processo produtivo `a área internacional. Além disso, o fato da empresa mostrar-se aberta a pesquisa e prover as informações necessárias a este estudo foi fator preponderante a sua escolha.

\section{Referencial teórico}

\subsection{Incentivos a exportação}

Segundo dados do Serviço Brasileiro de Apoio às Micro e Pequenas Empresas (2008), SEBRAE, essas, representam 98\% das empresas brasileiras dentro de um número de 5,1 milhões de empresas. Pode-se desta forma, indicar alguns pontos favoráveis que tornam o procedimento de exportação menos penoso e mais vantajoso para que as pequenas e médias empresas possam, igualmente, ter a oportunidade de se inserir no mercado internacional e obter competitividade junto às empresas de maior porte. Resende (1978) menciona como ponto favorecedor de exportações a compensação de tributos internos, anulação ou incidências mais moderadas sobre a alíquota de determinados tributos.

Castro (1999) indica quais são os tributos e suas respectivas isenções e/ou reduções. Produtos semi-elaborados ou industrializados, por exemplo, são imunes ao pagamento de IPI (Imposto sobre Produto Industrializado) e não há a incidência em ICMS (Imposto sobre Circulação de Mercadorias e Serviços), ademais da isenção do pagamento do COFINS (Contribuição para Financiamento da Seguridade Social) o qual tem incidência de 3\% sobre o faturamento das empresas e por fim a isenção do PIS (Programa de Integração Social) que tem incidência de 0,65\% sobre receita bruta.

Pode-se ainda, gerar créditos sobre esses tributos e utilizá-los em momento conveniente como na compra de matérias-primas, produtos intermediários, materiais de embalagem, entre outros, que são utilizados e destinados como processo produtivo de bens destinados à exportação.

Desta forma, as isenções, não-incidências e aquisições de crédito em relação aos tributos são frutos de uma política de incentivo a exportação, o que reduz os custos gerais e torna o produto final mais competitivo sob o aspecto do preço. 
Ademais aos aspectos tributários, existe a APEX - Agência Brasileira de Promoção de Exportações e Investimentos, como relata Lopez (2004), tem a função de incentivar as exportações, oferecendo apoio a implementação política de promoção de exportações, e atua disponibilizando informações comerciais, desenvolvendo e divulgando pesquisas de mercado, realizando eventos nacionais e internacionais, capacitando e treinando pessoal especializado em comércio exterior, entre outras funções.

Com os citados incentivos, a APEX apóia vários setores da economia, contribuindo desta forma para a diversificação dos itens exportados, abertura de novos mercados e sedimentação e ampliação dos mercados tradicionais e, particularmente, do crescimento notável nas vendas de itens com maior valor agregado.

Os benefícios são gerais e em todas instancias promovendo empresários que englobam as variadas composições de empresas, porém o foco é o incentivo a pequenas e médias empresas para seu desenvolvimento tanto no exterior quanto, conseqüentemente, em mercado interno.

\subsection{Micro e pequenas empresas do ramo médico-hospitalar-odontológico (MHO)}

A partir do estudo efetuado por Cezarino (2005), destaca-se o total de vinte e seis empresas do setor MHO na região de Ribeirão Preto, aponta que treze delas se encaixam nos parâmetros de micro empresa e dez no patamar de pequena, isso indica que $88 \%$ delas se encaixam nos padrões de MPE.

O SEBRAE indica que as micro e pequenas empresas podem ser assim classificadas de acordo com seu faturamento bruto anual, desta forma as microempresas serão assim qualificadas quando, auferirem em seu ano-calendário o montante igual ou inferior a $\mathrm{R} \$ 240.000,00$ e pequenas empresas, às que aufiram o montante superior a $\mathrm{R} \$ 240.000,00$ e igual ou inferior a $\mathrm{R} \$$ 2.400.000,00 em um período de exercício contábil, estes dados foram captados no ano de 2008 e são passíveis de variações.

Como representante do setor MHO a ABIMO, Associação Brasileira de Indústrias Médico Odontológicas, é segmentada em cinco setores diferentes os quais compreendem fabricantes de produtos do setor implantes e material de consumo médico-hospitalar, equipamentos médicohospitalares, setor de odontologia, setor de radiologia e diagnóstico por imagem e setor de laboratórios.

Os equipamentos médico-hospitalares compreendem mobiliário, eletromédicos, instrumental cirúrgico, equipamentos fisioterápicos e para hotelaria, utilizados em hospitais e clínicas médicas. Há ainda o ramo dos implantes destinados a usos ortopédicos, cardíacos, neurológicos e, por fim, materiais de consumo compreendem materiais hipodérmicos, têxteis e outros de uso médico. 


\subsection{Desafios da exportação nas micro e pequenas empresas}

Considerando, portanto a inserção das indústrias MPE do segmento MHO, Dias (2004), no âmbito da globalização, afirma que, exportar é algo necessário para o empresário brasileiro, pois quebrando e indo além das barreiras territoriais do país onde há um enorme mercado a ser explorado, existe proporcionalmente oportunidades de desenvolvimento.

O primeiro passo, para Minernivi (1997) assim como para Lopez (2004), diz respeito à necessidade de haver uma análise sobre a posição da empresa frente os desafios à exportação. Desta maneira, desenvolve-se um plano estruturado que busca salientar os requisitos para atuação em exportações, confrontando os dados com um diagnóstico das forças e fraquezas em dados atuais sobre a empresa. Desta forma, a empresa conhece sua real capacidade em relação à exportação e também seu posicionamento em relação a seus concorrentes.

Após estudos e definição do produto e/ou serviço a exportar, Minervini (1997) cita a importância de adaptá-lo ao mercado de destino, fatores como distância cultural, hábitos ou práticas mercadológicas, se mal geridas, podem levar todo o processo prévio desenvolvido ao fracasso. Obviamente que além desses fatores existem fatores técnicos que envolvem desde o design até a composição do produto comercializado.

Uma vez identificada à aceitabilidade do produto em determinado mercado, deve-se adotar um plano de ação que desenvolva metas, funções, planejamento e orçamento, planos de execução e pós-vendas para que todo o investimento no procedimento seja efetivamente satisfatório e para que continuamente traga os resultados esperados.

Dias (2004) então, menciona as exigências legais e administrativas para o procedimento formal de exportação. Primeiramente o exportador deve efetuar cadastramento no Siscomex, o qual é administrado pela Secretaria de Comércio Exterior, Secretaria da Receita Federal e pelo Banco Central do Brasil. O Siscomex faz controle e acompanhamento das operações.

Dentro dos padrões exigidos pelo Siscomex o exportador deve seguir, ademais, regras gerais para uso do sistema de nomenclaturas para padronização de informações sobre mercadorias além de uma estrutura documental fundamental para o devido encaminhamento do procedimento, tais como:

- Fatura proforma;

- Packing list;

- Registro de exportações;

- Commercial invoice;

- Registro de operações de crédito;

- Registro de vendas; 
- Declaração simplificada de exportações;

- Conhecimento internacional de embarque;

- Certificados e;

- Despacho aduaneiro.

A nomenclatura padronizada garante eficiência e seguridade sobre os tramites de exportação, para a o atendimento de uma série de conformidades as quais estão aliadas a um procedimento uniforme de estruturação com intuito de, também, agilizar o procedimento. Os documentos exigidos são itens que são obrigatoriamente vinculados ao progresso da exportação e garantem ademais todo o sistema de compensação, isenção e fiscalização do processo.

Existem inseridos no processo de exportação, citado por Minervini (1997), como instrumento de competitividade e para que se garanta a sustentabilidade do produto em mercados internacionais, três aspectos base de atendimento ao consumidor os quais são: qualidade, produção e preço.

A qualidade, por ser um aspecto subjetivo está sujeita a diferentes conceituações, mas o mínimo a se considerar para garantia esse adjetivo é a aplicação de práticas rigorosas que vão desde a escolha da matéria-prima até controles fabricação. Em produção, deve-se analisar se a empresa possui capacidade para atender a demanda de acordo com os planos de comercialização da empresa. E por último, porém, não menos importante, o preço, item consideravelmente delicado, pois é inerente ao exportador o controle do preço final do produto, visto que, este tem reflexo de todo o tramite, tais como encargos fiscais, variações cambiais além do custo fixo da empresa. Neste item o exportador terá que, continuamente, analisá-lo e reformulá-lo para criar pilares que o sustentem e não o deixem tão vulnerável as variações macro ambientais em vista de uma análise em longo prazo.

Faz-se, portanto, necessário que haja estudos que justifiquem a inserção de determinado produto em um mercado específico para que os esforços empregados em estruturação não sejam em vão e que todos os recursos e dispêndios sejam válidos tendo máximo retorno possível para o investidor. Adequar o produto ao mercado é, também, procedimento estratégico que garante maior aceitação e penetração em mercados específicos, simultaneamente deve-se alicerçar essa base estratégica no tripé qualidade, produção e preço. Desta forma resultados satisfatórios devem ser percebidos. 


\subsection{Registro e certificações}

Para maior garantia de sedimentação em mercados externos, além dos incentivos e benefícios já citados, devem-se adquirir certificados e registros os quais atestam padrões de saúde, procedimentos, produção, conformidades entre outros, os quais em alguns mercados possuem caráter de obrigatoriedade.

Lopez (2004) faz referência à necessidade do registro da marca do produto em mercado externo, a qual forma uma proteção ao seu direito de uso, em mercados desenvolvidos é inconcebível a prática de comercialização de produtos sem que marca do produto esteja registrada.

A marca CE - Certificado Europeu é um atestado de conformidade do Mercado Comum Europeu. Esta declara que o fabricante atende às exigências da norma européia dos produtos certificados, com respeito à diretiva da Comunidade Européia aplicável a essa norma.

Ricca (2004) acrescenta que a marca foi desenvolvida para facilitar o transito de mercadorias e serviços no bloco. Empresas que não atendem as normas ou não possuem a marca podem não conseguir comercializar seu produto dentro do bloco europeu.

Para a obtenção da certificação a empresa deve:

- Identificar qual norma é aplicável ao seu produto;

- Identificar o procedimento para avaliação de conformidade a ser utilizado;

- Identificar a existência de Padrões Europeus Harmonizados aplicáveis a seu produto;

- Garantir a aplicação às diretivas do certificado;

- Verificar a necessidade de auditoria para avaliação do processo;

- Manter a documentação técnica requerida;

- Preparar a Declaração de Conformidade e a documentação exigida;

- Analisar as exigências específicas a cada país;

- Agregar a marca CE ao produto.

Já a série ISO 9000 é um conjunto de normas que formam um padrão de gestão da qualidade para organizações que podem, certificar seus sistemas de gestão através de organismos de certificação. A sigla ISO em inglês denomina, Organização Internacional de Padronização. Para adquir a certificaçao da ISO 9000 a organização deve seguir alguns passos e atender alguns requisitos, dentre esses requisitos podemos citar: 
- A padronização dos processos chaves do negócio, processos que afetam o produto e conseqüentemente o cliente;

- Monitoramento e medição dos processos de fabricação para assegurar a qualidade do produto/serviço, através de indicadores de performance e desvios;

- Implementar e manter os registros adequados e necessários para garantir a rastreabilidade do processo;

- Inspeção de qualidade e meios apropriados de ações corretivas quando necessário; e

- Revisão sistemática dos processos e do sistema da qualidade para garantir sua eficácia.

Aliado ao registro as certificações são fundamentais e pré-requisitos para muitos países importadores. No caso das certificações, os selos que garantem a padronização do produto representam no mínimo a sua garantia em relação as variáveis que envolvem a produção e os demais procedimentos em determinados produtos nos vários dos segmentos existentes e o atendimento de exigencias técnicas para foco em determinado mercado como por exemplo o CE, desenvolvido para atendimento de padrões europeus. Esses selos garantem prestí́gio internacional e indubitavelmente maior reconhecimento e valoração do produto em mercado interno.

\section{Unidade-caso}

A Dentflex Indústria e Comercio LTDA, é uma empresa inserida no patamar de EPP Empresa de Pequeno Porte. Atende ao setor médico e odontológico, é atuante no mercado há cerca de dezesseis anos e conta com vinte e dois funcionários, a companhia gera por volta de R\$1.100.000,00 ao ano, está implantada em Ribeirão Preto - São Paulo, cidade qual tem grande representatividade na produção de materiais odontológicos. Possui pontos de revenda localizados em diversos estados do Brasil, como também no mundo, além de assistência técnica especializada e desenvolvida pela companhia.

A Dentflex fabrica os seus produtos e os vende, em sua maioria, a distribuidores os quais estão localizados em grande parte do território nacional, estes são responsáveis por cerca de 75\% de seu faturamento, os $30 \%$ restantes são relacionados a vendas ao mercado externo tais como, América Latina, Leste Europeu, Oriente Médio, África, Ásia e Oceania.

Seus produtos são desenvolvidos para quatro tipos de consumidor, sendo eles: 
- Kit Acadêmico e articulador, material desenvolvido especialmente a indivíduos que estão em período de graduação em odontologia;

- Endodontia e Implante, material também desenvolvidos para estudantes, porém, são designados a áreas mais especificas como especializações;

- Concorrências públicas, vendas efetuadas a União, Estado e Município;

- Dentais assim denominadas as empresas distribuidoras de produtos odontológicos as quais representam uma relevante parcela de sua carteira de clientes.

Devem-se considerar dois fatores básicos para a escolha de Ribeirão Preto para a montagem do empreendimento, primeiramente os fundadores da fábrica provem de outra empresa que atua no mesmo segmento nesta cidade, portanto, detiveram conhecimento suficiente para iniciar seu próprio empreendimento, o segundo fator a ser considerado é o fato de Ribeirão Preto ser pólo na América Latina em segmento odontológico, portanto neste ambiente tem-se maior quantidade de mão-deobra especializada e maiores recursos para seu procedimento empresarial.

O mix de produtos é diversificado e existe um considerável número de empresas que produzem os mesmos produtos no segmento odontológico e atuam no mesmo nicho de mercado. Para os Articuladores existem dois fortes concorrentes sendo a Bio Arte, como concorrente nacional, a qual possui fábrica instalada em São Carlos e a Whip Mix a qual é norte-americana e representa concorrência internacional. Peças de Mão (canetas, micromotor, contra-ângulo, etc.), concorrem com indústrias multinacionais como a alemã Kavo, austríaca WH, suíça Bienair e japonesa NSK e com as Ribeirão Pretanas Dabi Atlante, Gnatus, Dentscler, Microdent e DX.

A Dentflex destina cerca de $7,5 \%$ de seu faturamento bruto para planejamento e desenvolvimento, com uma visão pró-ativa busca sedimentar procedimentos para maximizar todo o processo desde a compra da matéria-prima até o pós vendas. Também fabrica produtos a preços acessíveis, porém não se é desvinculada a qualidade ao seu produto.

A Dentflex dispõe de uma área útil de $1000 \mathrm{~m}^{2}$, e está instalada em um dos bairros industriais no município. A empresa não possui filial e este imóvel referido é sua única instalação firmada, sua marca, porém difunde-se através de seus distribuidores. Possui uma produção mensal que gira em torno de 150 peças acabadas de cada modelo, o que são 750 peças em seu total.

Em sua planta a empresa constitui-se dos sistemas necessários para sua gestão e funcionamento, tais como: Departamento Financeiro o qual gere as contas a pagar, despesas e efetua o pagamento do salário dos colaboradores da empresa, as demais funções sobre a área financeira são efetuadas por uma empresa de contabilidade terceirizada, no Recurso Humano (RH) é efetuado o recrutamento, seleção, análise de desempenho, análise e qualidade de vida no ambiente da empresa, admissões e demissões. Há também o Marketing e Vendas que desenvolvem a 
promoção dos produtos da empresa por intermédio de ferramentas como banners, site, catálogos entre outros. O departamento de Engenharia é responsável pelo desenvolvimento técnico dos produtos para que esses sejam produzidos. Por fim, o setor de Comércio Exterior fica a cargo da exportação e eventuais importações dos produtos e equipamentos utilizados na Dentflex. Para exportações todo o trâmite é desenvolvido por um funcionário contando com o apoio de um estagiário, o tramite de importação é feito através de uma empresa terceirizada para a execução do processo. A Diretoria, cargo ocupado por um dos sócios da empresa, rege e mantém o funcionamento dos departamentos da Dentflex e setores de produção e montagem os quais são responsáveis por montar os produtos transformando-os em material acabado.

A direção assegura que as responsabilidades e autoridade estão definidas e são comunicadas a organização. Estas estão definidas nos procedimentos documentados do Sistema de Gestão da Qualidade (SGQ) e nas Instruções de Trabalho.

Para o devido comprometimento com a qualidade dos produtos e processos é órgão presente o Sistema de Gestão da Qualidade (SGQ), o qual inclui a Declaração documentada da Política da Qualidade e dos Objetivos da Qualidade - Manual da Qualidade; Procedimentos Documentados requeridos pelas normas NBR ISO 9001:2000 e ISO 13485:2003; além disso, ainda há documentos necessários a Dentflex para assegurar o planejamento, a operação e o controle eficazes de seus processos etc.

Logo a Dentflex identificou os processos necessários para o SGQ e sua aplicação por toda a organização, determinou seqüências, métodos e critérios a fim de garantir que a operação e controle de seus produtos sejam eficazes. Além de assegurar disponibilidade de recursos e informações, monitoramento dos processos e pró-atividade para maximização dos procedimentos de produção. Tudo em vista da otimização de cada sistema que integra o funcionamento geral da empresa para que desta forma possa-se conseqüentemente alcançar a satisfação de seus clientes.

\section{Resultados da análise}

O início do processo de exportação da empresa denota que as condições de mercado internacional foram às principais causas para o início de sua internacionalização. Percebe-se que só a partir de 2003 houve uma junção de fatores como câmbio favorável, condições internacionais de crescimento e busca por maiores canais de venda para a produção excedente da empresa o que resultou na vontade da empresa em iniciar um processo exportador.

Outro fator mencionado na entrevista foi a isenção de impostos para o exportador brasileiro. O respondente afirma que a isenção de impostos com incidência direta nos custos como IPI, ICMS, 
PIS e COFINS reflete em maior competitividade em relação ao preço final tornando o produto mais atrativo.

Contribuíram também incentivos governamentais, como a ABIMO (Associação Brasileira de Indústrias Médico Odontológicas), órgão vinculado a APEX (Agência Brasileira de Promoção de Exportação) que oferece às empresas do segmento odontológico apoio como consolidação de stands em feiras internacionais, pesquisas de mercados, missões empresariais, rodadas de negócios, entre outras, as quais proporcionam maior facilidade para inserir-se em mercado externo, principalmente às empresas de pequeno porte como a DentFlex que não possui capital suficiente para destinar a essas variáveis fundamentais do setor.

Além de que na época em que se iniciou a exportação, ano de 2003, o câmbio de paridade Real x Dólar mostrava-se favorável cotado a média de USD 1,00=R $\$ 3,00$.

Quanto às mudanças na estrutura e modelo de negócio de gestão, as alterações se mostraram bastante significativas. As mudanças foram muitas, entre elas, registro na Receita Federal como empresa exportadora, capacitação de funcionários do setor comercial em relação a procedimentos operacionais e comerciais da exportação, investimento em capacitação de funcionários quanto à aprendizagem de novos idiomas, até mesmo o proprietário da empresa começou a estudar inglês e espanhol. Criação de preços especiais para o mercado externo e em outras moedas como dólar e Euro, modificações nos produtos para adequação aos mercados em questão. Certificações nacionais e internacionais como Boas práticas de fabricação, ISO, marcação CE.

O momento em que se percebeu a necessidade de certificação pela empresa foi no período em que a empresa estava perdendo várias oportunidades de negócios, pois algumas certificações são pré-requisito para participação em licitações, inserção em mercados específicos, como por exemplo, o europeu e até mesmo outros mercados que apesar de não participar da comunidade européia adotam as mesmas diretrizes tais como Turquia, Irã, Egito entre outros, afirmou o respondente.

Além de que, percebeu-se que uma certificação internacional poderia alavancar o mercado interno uma vez que essa asseguraria padrão de qualidade internacional ao produto e com isso agregaria maior credibilidade à marca.

Inicialmente procurou-se uma empresa especializada em implantação de certificações internacionais, a mesma prestou serviço de consultoria a DentFlex auxiliando-a na interpretação das normas e adequação dos procedimentos em relação as mesmas.

O processo iniciou-se no final do ano de 2005 quando se contratou a empresa certificadora e consultora para adequação e certificação ISO e CE, posteriormente fora instruído para que se criasse um departamento de qualidade e a contratação de um funcionário especializado que administrasse os requisitos das normas de certificação e mantivesse a organização processual envolvida dos requisitos regulatórios na empresa. A conscientização de todos os envolvidos na 
empresa durante a implantação e manutenção do processo foi um fator crítico, pois além das necessidades especificas a certificação existia a necessidade de mudança de cultura empresarial.

O processo de implantação instruiu a mudança de meios para aprimorar os processos, a existência de ruídos entre a comunicação da diretoria com os funcionários além da forte cultura empresarial impregnada não deixavam as metas claras e tornava os funcionários resistentes às adequações. Por muitas vezes os funcionários enxergavam os processos desnecessários e irrelevantes considerando-os apenas como meio de coibi-los e restringi-los a execução de seu serviço. Não eram claras as intenções da diretoria aos funcionários as metas para o objetivo almejado.

Portanto, foram necessárias seguidas reuniões e comunicados para a conscientização de todos à adequação aos requisitos aprobatórios.

Com as certificações a empresa conseguiu maior alcance de mercado e amplitude de atuação, pois essa conseguiu ingressar em mercados que possuem tal requisito como pré-aprovação para inserção do produto. Além da questão já mencionada que diz respeito a credibilidade em mercado interno, na qual uma certificação internacional agrega representatividade a marca alavancando também as vendas nacionais com isso gerando maior receita e posterior lucratividade.

Atualmente a DentFlex exporta para mais de quarenta países localizados nos cinco continentes, antes de possuir as certificações exportava para uma média de quinze países, em sua maioria da América Latina por não possuir requisitos tão rigorosos em relação a certificações, geradas por benefícios de acordos econômicos bilaterais como isenção e/ou redução tributária e proximidade geográfica.

Para mercados externos a certificação funciona como uma espécie de apêndice ao produto, visto que além do certificado existe a necessidade de atender a outros requisitos tal qual tecnologia, caso ele não atenda uma das especificidades de cada localidade a certificação não representa um diferencial.

A DentFlex não emprega forte propagandas de marketing em relação aos certificados no mercado internacional devido ao baixo investimento e reservas destinadas a esse setor, assim a marca não tem grande reconhecimento externo e conseqüentemente não se tem conhecimento sobre seus atributos em relação a certificação e até mesmo qualidade.

\section{Considerações finais}

Após análise dos dados coletados e comparados da empresa em questão, pode-se fazer análise que a Dentflex não nasceu com intuito de exportar, porém no decorrer do tempo verificou-se a chance de ingresso através da combinação entre oportunidades efêmeras de mercado, como por 
exemplo, taxa cambial favorável, incentivos fiscais, como isenções tributárias e existência de órgãos governamentais de suporte e apoio as empresas do segmento: ABIMO.

Desta forma ao ingressar-se em mercado internacional a DentFlex verificou a necessidade de implementar certificações para alcançar novos mercados os quais propunham a certificação como pré-requisito para o ingresso do produto em seu mercado, neste contexto a Europa, quando então, em 2005 iniciou-se o processo de certificação ISO e CE.

Para que a DentFlex fosse certificada ela teria que passar pela adequação e padronização ditados pelas diretrizes de cada regulamento, desta forma deu-se a contratação de uma empresa a qual presta consultoria e é uma certificadora, a qual atesta que os padrões exigidos são atendidos. Após a reestruturação de meios produtivos, processuais e também cultural o qual representa um dos fatores mais dispendiosos para mudanças, aplicou-se a DentFlex o títulos de empresa certificada ISO 9001:2000, ISO 13485:2003 e marcação CE.

Com isso ela conseguira o "visto" de entrada para os países da Europa e alguns outros que ficam sob suas mediações e adotam diretrizes de certificação semelhante.

Indubitavelmente a certificação internacional não assegura a venda do produto e não é necessária para exportação em uma análise de um contexto genérico, esta apenas indica que o produto segue padrões estipulados por diretrizes da norma vigente e selo certificador, elas apenas atestam que determinado produto certificado atende a uma série de requisitos pré-estipulados. Desta forma alguns mercados adotam ou criam suas próprias exigências de ingresso de produtos o que faz com que as empresas que têm interesse em atuar nesse nicho tenham que se adequar.

Para mercados que não exigem certificação, tê-la significa um diferencial, pois assegura o mínimo de qualidade ao produto, portanto, pode alavancar vendas frente a um produto que não a tem.

Conclui-se que a partir do momento que uma empresa resolver atuar no mercado externo ela pode decidir aumentar sua abrangência de mercado adquirindo certificações que são requisitos de ingresso em determinadas localidades e assim aumentar sua abrangência de atuação em mercado externo, porém para tal ela tem que passar por mudanças internas que atendam as exigências estipuladas, desta forma dá-se a contratação de uma empresa especializada que tem a concessão de prestar consultoria, auditar e certificar, a partir de então a empresa passará por adequações rotineiras, burocráticas e culturais para atender a especificidade do selo que almeja, explicitando dessa forma as questões organizacionais envolvidas para que a empresa seja certificada.

Ficou clara a importância nas condições de mercado internacional e a necessidade de certificação da produção da empresa como exigência para venda. Nota-se mudanças significativas no que tange à profissionalização dos processos internos e a conscientização da empresa pela busca de melhorias contínuas para manter-se no mercado global. O valor deste trabalho está na 
contribuição que ele forneceu às condições, razões e conseqüências de gestão de implantação de certificação em uma pequena manufatura do setor médico, hospitalar e odontológico para compreensão da internacionalização de pequenas empresas brasileiras.

\title{
8 Limitações e futuras pesquisas
}

Como principal limitação desta pesquisa é apontado o fato de não poder generalizar seus relatos à todas empresas de pequeno porte neste setor. $\mathrm{O}$ que se pode afirmar que as condições internacionais forçaram a certificação nesta empresa bem como exigiram profissionalização de seus processos. Para o futuro pesquisar as empresas de Ribeirão Preto que são exportadoras ou que lidam com este setor para estabelecer um padrão de comportamento organizacional poderia render maiores contribuições à literatura de administração de produção.

\begin{abstract}
The article investigates the export certification conditions which small business in medical, dental and healthy sector deals in Ribeirão Preto. Exploratory, by case study were observed that principle cause were external to organizations. International market, change and others factors were favorable to the sales of this kind of problem to conduct to certification. All process was managed by external agents like consultants $\mathrm{e}$ the certification was used to create marketing differential to the organization. As final considerations it was perceived that the export process was reactive and with no alignment to strategic planning but responsible for relevant change in organizational internal process.
\end{abstract}

Key-words: export; small business; certification.

\section{Referências}

AGÊNCIA BRASILEIRA DE PROMOÇÃO DE EXPORTAÇÕES E INVESTIMENTOS - APEX. Principal > quem é quem. Disponível em: <http://www.apexbrasil.com.br/interna.aspx?id=1> . Acessado em: 07/04/08.

ASSOCIAÇÃO BRASILEIRA DA INDÚSTRIA DA MADEIRA PROCESSADA MECANICAMENTE ABIMCI. Certificação CE. Disponível em: <http://www.abimci.com.br/certificacao_ce.html>. Acesso em: 07/04/08.

ASSOCIAÇÃO BRASILEIRA DE INDÚSTRIAS MÉDICO ODONTOLÓGICAS - ABIMO. Abimo/Sinaemo. Disponível em: $<$ http://www.abimo.org.br/default_interno.asp> Acesso em: 07/04/08.

BANCO NACIONAL DE DESENVOLVIMENTO ECONÔMICO E SOCIAL - BNDES. Conhecimento. Disponível em: <http://www.bndes.gov.br/conhecimento/bnset/set1906.pdf> Acesso em 0206/2008.

BOYD, Westfall. STASCH. Marketing Research: texts and cases. Illinois: Richard Irwin, 1985.

CAMPOMAR, M. C. Do uso do Estudo de Caso em Pesquisas para Dissertações e Teses em Administração. RAUSP. V.26.n.3p.95-97.julho/setembro, 1991.

CAStro, C. M. A Prática da Pesquisa. São Paulo: McGrawHill,1977. 
CAStro, J. A. Exportação Aspectos Práticos e Operacionais. São Paulo: Aduaneiras, 1999.

CERVO, A. L. Metodologia Científica. 6 edição. São Paulo: Pearson Prentice Hall, 2007.

CEZARINO, O. L.. Um estudo de clusters e arranjos produtivos locais: uma aplicação em micro e pequenas empresas. São Paulo, 2005. Dissertação de Mestrado. Faculdade de Economia, Administração e Contabilidade. FEA/USP.

DIAS; R. Comércio Exterior Teoria e Gestão. São Paulo: Atlas, 2004. GARCIA, E. A. C. Manual de Sistematização e Normalização de Documentos Técnicos. São Paulo: Atlas, 1998.

GIL, A. C. Como elaborar projetos de pesquisa. 3 edição. São Paulo: Atlas, 1991.

GOLDENBERG, M. A arte de pesquisar: como fazer pesquisa qualitativa em Ciências Sociais. Rio de Janeiro: Record, 1999.

LOPEZ, J. M. C; GAMA, M. Comércio Exterior Competitivo. São Paulo: Aduaneiras, 2004.

LUCIO, G. C.; FIGUEIREDO, A.; KARAM, N. O câmbio e suas influências na economia. São Paulo, maio 2006, Nota técnica. Disponível em: <http://www.dieese.org.br/notatecnica/notatec24cambio.pdf> Acesso em: 07/04/08.

MINERVINI, N. Exportar: Competitividade e Internacionalização Guia Prático do Exportador. São Paulo: Makron Books, 1997.

OLIVEIRA, S. L. Tratado de Metodologia Científica. São Paulo: Pioniera: 1997.

RESENDE, L. S. Exportação: Organização para Exportar, Rotinas e Procedimetos, Canais de Distribuição. São Paulo: Atlas, 1978.

RICCA, J. L. Manual Básico de Exportação. 1 edição. São Paulo: SEBRAE 2004.

ROBBINS, S. P. Administração Mudanças e Perspectivas. São Paulo: Atlas 2000.

SERVIÇO DE APOIO AS MICRO E PEQUENAS EMPRESAS - SEBRAE. A lei geral e o conceito de MPE. Disponível em: http://www.sebraesp.com.br/topo/pol\%C3\%ADticas\%20p\%C3\%BAblicas/faq_lei_geral/conceito.aspx> Acesso em: 07/04/08.

SERVIÇO DE APOIO AS MICRO E PEQUENAS EMPRESAS - SEBRAE. Conhecendo as Micro e Pequenas Empresas. Disponível em:

http://www.sebraesp.com.br/principal/conhecendo $\% 20 \mathrm{a} \% 20 \mathrm{mpe} / \mathrm{mpes} \% 20 \mathrm{em} \% 20 \mathrm{n} \% \mathrm{C} 3 \% \mathrm{BAmeros} />$ Acesso em: $21 / 09 / 08$.

VAZQUEZ, J. L. Comércio Exterior Brasileiro. Siscomex Importação e Exportação. 4ª ed. São Paulo: Atlas 1999.

\section{Dados dos autores:}

Nome completo: Luciana Oranges Cezarino

Filiação institucional: Faculdade de Economia, Administração e Contabilidade da Universidade de São Paulo - FEA/USP; Universidade de Ribeirão Preto - UNAERP.

Departamento: Administração.

Função ou cargo ocupado: Doutoranda e Professora.

Endereço completo para correspondência: Rua Professor Antonio Palocci, 700 casa 23. Jardim Ouro 
Branco. Ribeirão Preto - SP. CEP 14079-800.

Telefones para contato: 16- 36184788 e 92350093

e-mail:1ucezarino@hotmail.com

Nome completo: Hamilton Luiz Corrêa

Filiação institucional: Faculdade de Economia, Administração e Contabilidade da Universidade de São Paulo - FEA/USP.

Função ou cargo ocupado: Professor Doutor.

Endereço completo para correspondência: Avenida Luciano Gualberto, 908 FEA 1 sala G-156.

Cidade Universitária. São Paulo-SP. CEP: 05508-900.

Telefones para contato: 11-30915987.

e-mail:hamillco@usp.br

Nome completo: Helds Massashi Ishi

Filiação institucional: Universidade de Ribeirão Preto - UNAERP.

Função ou cargo ocupado: Graduando.

Endereço completo para correspondência: Av. Costábile Romano, 2.201 Ribeirânia - Ribeirão Preto-SP CEP 14096-900.

Telefones para contato: 16 - 99924243

e-mail:heldaoxxx@hotmail.com 